\title{
Septo-optic dysplasia and WS1 in the proband of a WS1 family segregating for a novel mutation in PAX3 exon 7
}

\author{
Melisa L Carey, Thomas B Friedman, James H Asher Jr, Jeffrey W Innis
}

\section{Department of Zoology, Michigan \\ State University, East \\ Lansing, Michigan \\ 48824, USA \\ M L Carey* \\ T B Friedmant \\ J H Asher Jr}

Graduate Program in Genetics, Michigan State University, East Lansing, Michigan 48824, USA

T B Friedman

$\mathrm{J}$ H Asher Jr

\section{Department of}

Pediatrics and Human

Development,

Michigan State

University, East

Lansing, Michigan

48824, USA

T B Friedman

J H Asher Jr

\section{Departments of}

Human Genetics and

Pediatrics, University

of Michigan, Medical

Science II, M4708, Ann

Arbor, Michigan

48109-0618, USA

$\mathrm{J} W$ Innis

Correspondence to:

Dr Innis.

${ }^{\star}$ Present address: Human

Genome Sciences Inc,

Department of Protein

Therapeutics, $9620 \mathrm{Key}$ West Avenue, Rockville, Maryland 20850, USA.

†Present address: National Institute on Deafness and Other Communication Other Communication

Disorders, National

Institutes of Health, 5

Maryland 20850, USA.

Received 12 May 1997 Revised version accepted for publication 5 September 1997

\begin{abstract}
A four generation family (UoM1) was ascertained with Waardenburg syndrome type 1 (WS1). The proband exhibited both WS1 and septo-optic dysplasia. A G to $C$ transversion was identified in PAX3 exon 7 in four subjects affected with WS1 in this family including the proband. This glutamine to histidine missense mutation at position 391 may also affect splicing. There are over 50 mutations characterised in PAX3 in WS1 patients; however, this is the first example of a WS1 mutation in exon 7 of PAX3.
\end{abstract}

(F Med Genet 1998;35:248-250)

Keywords: Waardenburg syndrome; septo-optic dysplasia; PAX3

Waardenburg syndrome (WS) is an autosomal dominant disorder characterised by pigmentary and facial anomalies, deafness, and other clinical traits. ${ }^{1-3}$ There are four clinical subtypes of WS, WS1 (OMIM 193500), WS2 (OMIM 193510), WS3 (OMIM 148820), and WS4 (OMIM 277580). Mutations in WS1 and WS2 have been identified in PAX3 and MITF, respectively. ${ }^{14-21}$ We report a WS1 family (UoM1) in which the proband has both WS1 and septo-optic dysplasia (SOD). SOD is a sporadic developmental malformation of the anterior midline structures of the brain encompassing a spectrum of optic nerve hypoplasia, hypoplasia of the chiasm and primitive optic ventricles, absence or hypoplasia of the septum pellucidum and infundibulum, partial or complete absence of the corpus callosum, and neuroendocrine deficiencies. ${ }^{22}$ There are no published reports of WS1 and SOD occurring in the same person and no mutations reported to be associated with SOD. We screened for mutations in PAX3 and MITF in this four generation WS1 family and also in six unrelated subjects with isolated SOD.

\section{Methods}

The family (fig 1A) was ascertained at the University of Michigan Pediatric Genetics Clinic. Patients with SOD were ascertained through the University of Michigan Pediatric Endocrinology Clinic. The father of the proband has Waardenburg syndrome type I (fig 1A). He was examined by MRI for SOD and was found to be normal. DNA was isolated from blood using the PUREGENE kit (Gentra Systems). The proband of UoM1, 33 unrelated WS1, WS2, and WS4 patients, 60 random subjects without
WS, and six unrelated subjects with SOD were screened for mutations. The polymerase chain reaction (PCR) was performed for the eight exons of PAX3 and the nine exons of MITF as described previously ${ }^{1213171921}$ followed by single strand conformation polymorphism (SSCP) analysis on $\mathrm{MDE}^{\mathrm{TM}} 0.5 \times$ Hydrolink $^{\mathrm{R}}$ gel (AT Biochem). Electrophoresis was performed at $8 \mathrm{~W}$ at room temperature with and without $10 \%$ glycerol. Relevant DNA fragments were cloned into a $\mathrm{pGEM}^{\mathrm{R}}-\mathrm{T}$ Vector System (Promega) and sequenced using Sequenase Version 2.0 (Amersham). Cycle sequencing reactions were performed following the manufacturer's protocol using the $\Delta T a q$ Cycle Sequencing kit (Amersham). A mutant allele specific primer (TF195: CTAGAAACACGGGACTGACG), the normal upstream exon 7 primer (TF141: AGAAAACATGATGGTTGACAATC), and a PAX3 exon 4 primer pair as a control were used for allele specific PCR amplification.

\section{Results and discussion}

In the proband of UoM1 a SSCP variant was detected in PAX3 exon 7. The SSCP variant was not observed in the 33 unrelated WS1, WS2, and WS4 patients nor in 60 random subjects. Affected members of UoM1 have a $G$ to $C$ transversion in PAX3 exon 7 (fig 1B). Four WS1 patients in the family (II.2, III.3, III.2, IV.2), including the proband with WS1 and SOD, amplified both the mutant allele specific fragment $(270 \mathrm{bp})$ and the control fragment $(242 \mathrm{bp}$ ) (fig 1C). Only the control fragment PCR amplified in the unaffected mother (III.4) and in 60 random subjects. Thus, the $G$ to $C$ transversion in PAX3 exon 7 is not a common polymorphism and is probably the basis of WS1 in this family. Although more than $\mathbf{5 0}$ mutations have been identified in PAX 3 in WS 1 patients, the $Q 391 \mathrm{H}$ substitution is the first mutation in PAX3 exon 7 (fig 2). This substitution has several potential effects on the expression of PAX3. First, glutamine 391 is replaced with histidine $(\mathrm{Q} 391 \mathrm{H})$. Second, since Q391H changes an important nucleotide in a $5^{\prime}$ splice site, it is reasonable to hypothesise that the Q391H PAX3 mutation could cripple normal PAX3 premRNA splicing resulting in aberrantly spliced transcripts. ${ }^{24}{ }^{25}$ An identically positioned $G$ to $C$ transversion at the end of exon 1 in the $\beta$ globin gene was shown to inhibit almost completely correct splicing in cell free extracts. ${ }^{26} \mathrm{~A}$ drastically reduced amount of Q391H substituted PAX3 protein together with products altered in the transactivation domain could 


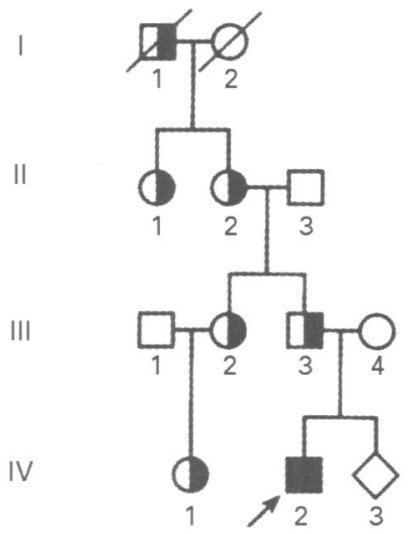

B

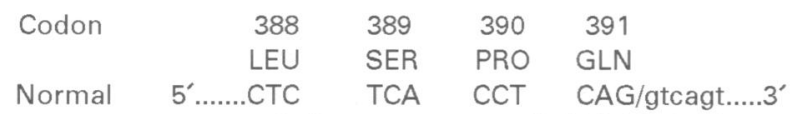

Splice consensus (C/A)AG/gt/a/g)agt

Mutant $5^{\prime}$.......CTC TCA CCT CAC/gtcagt...... LEU SER PRO HIS

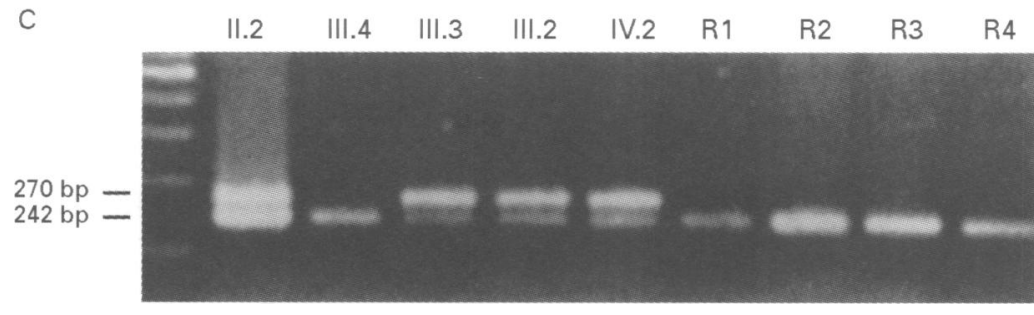

Figure 1 (A) Pedigree of UoM1. The right half of the symbols is filled in to represent the WS phenotype and the left half is filled in to represent SOD. (B) Codons 388 to 391 of $P A X 3$ exon 7 showing the $Q 391 \mathrm{H}$ mutation in family UoM1. (C) PCR amplification of DNA from WS patients (II.2, III.2, III.3, IV.2) show both the 270 and 242 base pair fragments while amplification of DNA from the unaffected mother (III.4) and the four random samples $(R)$ show only the 242 base pair control $P C R$ product. theoretically be produced. No other sequence variations in PAX 3 and MITF were detected in the proband and no PAX 3 or MITF sequence variants were detected in any of six unrelated subjects with SOD. A connection between WS1 and SOD could not be established in this study. There are over 50 mutations reported in PAX3 and Q391H is the first example of a PAX3 exon 7 mutation associated with WS1.

We would like to thank the UoM1 family and the six people with SOD for participating in this study. We thank Dr Nancy Hopwood and Kathy Clark, MSN for their help in obtaining the SOD patient material. We also thank Dr James Brunberg for evaluation of the head MRI of the proband's father. This work was supported by grant R01 DC01160-02 from the National Institute on Deafness and Other Communication Disorders to JHA and TBF. JWI is supported by R29 34059 from NIH and by UM-MAC Center Grant NIH P60 AR20557. This paper is dedicated to our co-author and friend Dr James $\mathrm{H}$ Asher Jr who died on 13 May 1996.

1 Farrer LA, Arnos KS, Asher JH Jr, et al. Locus heterogeneity for Waardenburg syndrome is predictive of clinical subtypes. Am f Hum Genet 1994;55:728-37.

2 Klein D. Historical background and evidence for dominant inheritance of the Klein-Waardenburg syndrome (type III). Am 7 Med Genet 1993;14:231-9.

3 Waardenburg PJ.A new syndrome combining developmental anomalies of the eyelids, eyebrows and nose root with pigmentary defects of the iris and head hair with congenital pigmentary defects of the iris and head hair with

4 Asher JH Jr, Morell R, Friedman TB. Waardenburg syndrome (WS): the analysis of a single family with a WS1 mutation showing linkage to RFLP markers on human chromosome 2q. Am f Hum Genet 1991;48:43-52.

5 Asher JH Jr, Sommer A, Morell R, Friedman TB. Missense mutation in the paired domain of $P A X 3$ causes craniofacial-deafness-hand syndrome. Hum Mutat 1996;7: 30-5.

6 Baldwin CT, Hoth CF, Amos JA, da-Silva EO, Milunsky A. An exonic mutation in the HuP2 paired domain gene causes Waardenburg's syndrome. Nature 1992;355:637-8.

7 Baldwin CT, Lipsky NR, Hoth CF, Cohen T, Mamuya W, Milunsky A. Mutations in PAX3 associated with WaardenMurg syndrome type I. Hum Mutat 1994;3:205-1 1.

8 Baldwin CT, Hoth CF, Macina RA, Milunsky A. Mutations in $P A X 3$ that cause Waardenburg syndrome type I: ten new in $P A X 3$ that cause Waardenburg syndrome type 1 : ten new mutations and

9 Foy C, Newton V, Wellesley D, Harris R, Read AP. Assignment of the locus for Waardenburg syndrome type I to human chromosome $2 \mathrm{q} 37$ and possible homology to the Splotch mouse. Am f Hum Genet 1990;46:1017-23.

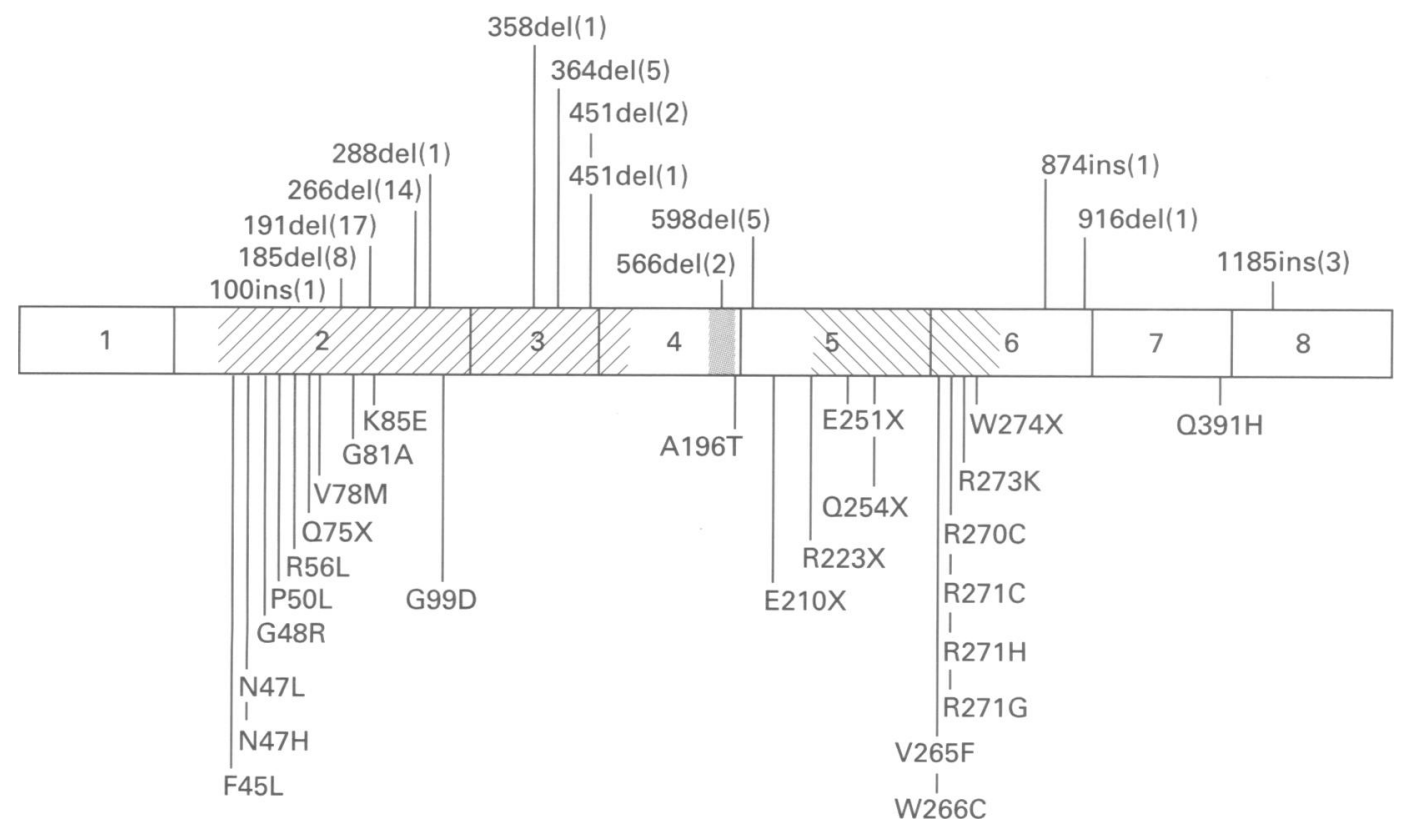

Figure 2 Diagram of the PAX3 gene with published locations of mutations in relation to the eight exons and the DNA binding domains. The mutations above the gene diagram represent deletions and insertions designated by the nucleotide position and those below represent missense and nonsense mutations designated by the amino acid sequence. The paired domain is designated with right diagonal lines within exons 2,3 , and a portion of 4 , the octapeptide domain is designated with closed circles within exon 4, and the homeodomain is designated with left diagonal lines within portions of exons 5 and 6. 
$10 \mathrm{Hol}$, FA, Hamel BC, Geurds MP, et al. A frameshift mutation in the gene for $P A X 3$ in a girl with spina bifida and mild signs of Waardenburg syndrome. 7 Med Genet $1995 \cdot 32 \cdot 52-6$.

11 Hoth CF, Milunsky A, Lipsky N, Sheffer R, Clarren SK, Baldwin CT. Mutations in the paired domain of the human $P A X 3$ gene cause Klein-Waardenburg syndrome (WSIII) as well as Waardenburg syndrome type I (WSI). Am $\mathcal{f}$ Hum Genet 1993;52:455-62.

12 Lalwani AK, Brister JR, Fex J, et al. Further elucidation of the genomic structure of $P A X 3$, and identification of two different point mutations within the $P A X 3$ homeobox that cause Waardenburg syndrome type 1 in two families. $A m \mathcal{F}$ Hum Genet 1995;56:75-83.

13 Morell R, Friedman TB, Moeljopawiro S, Hartono, Soewito, Asher JH Jr. A frameshift mutation in the HuP2 paired domain of the probable human homolog of murine Pax-3 is responsible for Waardenburg syndrome type 1 in Pax-3 is responsible for Waardenburg syndrome type

14 Morell R, Carey ML, Lalwani AK, Friedman TB, Asher JH Jr. Three mutations in the paired homeodomain of PAX3 th. Three mutations in the paired homeodomain of PAX3 that cause Waard

15 Morell R, Friedman TB, Asher JH Jr. A plus-one frameshift mutation in $P A X 3$ alters the entire deduced amino acid sequence of the paired box in a Waardenburg syndrome type I (WSI) family. Hum Mol Genet 1993;2:1487-8.

16 Pandya A, Xia-Juan X, Landa BL, et al. Phenotypic variation in Waardenburg syndrome: mutational heterogeneity, modifier genes or polygenic background? Hum Mol Genet 1996;5:497-502.

17 Tassabehji M, Read AP, Newton VE, et al. Waardenburg syndrome patients have mutations in the human homo- logue of the Pax-3 paired box gene. Nature 1992;355:635-

18 Tassabehii M, Read AP, Newton VE, et al. Mutations in the $P A X 3$ gene causing Waardenburg syndrome type 1 and type 2. Nat Genet 1993;3:26-30.

19 Tassabehji M, Newton VE, Read AP. Waardenburg syndrome type 2 caused by mutations in the human microsyndrome type 2 caused by mutations in the human
phthalmia $(M I T F)$ gene. Nat Genet 1994;8:251-5.

20 Tassabehji M, Newton VE, Leverton $\mathrm{K}$, et al. PAX3 gene structure and mutations: close analogies between Waardenburg syndrome type I and the Splotch mouse. Hum Mol Genet 1994;3:1069-74.

21 Tassabehji M, Newton VE, Liu X, et al. The mutationa spectrum in Waardenburg syndrome. Hum Mol Genet 1995;4:2131-7.

22 Brook CG, Sanders MD, Hoare RD. Septo-optic dysplasia. $B M \Im$ 1972;3:811-13.

23 de Morsier G. Median cranioencephalic dysraphias and olfactogenital dysplasia. World Neurol 1962;3:485-500.

24 Krawczak M, Reiss J, Cooper DN. The mutational spectrum of single base-pair substitutions in mRNA splice junctions of human genes: causes and consequences. Hum Genet 1992;90:41-54.

25 Shapiro MB, Senapathy P. RNA splice junctions of different classes of eukaryotes: sequence statistics and functional implications in gene expression. Nucleic Acids Res 1987;15: 7155-74.

26 Vidaud $M$, Gattoni $R$, Stevenin J, et al. A 5 ' splice-region $\mathrm{G} \rightarrow \mathrm{C}$ mutation in exon 1 of the human $\beta$-globin gene inhibits pre-mRNA splicing: a mechanism for $\beta+$ thalassemia. Proc Natl Acad Sci USA 1989;86:1041-5. 